\title{
An Approach for the Experimental Research Studies in Engineering: (Investigation Curiosity Analysis Design)
}

\author{
Melda Özdinç ÇARPINLIOĞLU \\ Mechanical Engineering Department \\ University of Gaziantep \\ Gaziantep, Turkey
}

\begin{abstract}
In this paper, an approach utilized for the experimental research studies in the content of the graduate program of mechanical engineering is outlined. Although a variety of study topics in the covered time period of 2012- 1997 is concerned it is proposed that the followed algorithm can be applied in different fields of engineering science. The performance of the algorithm is presented through the introduced parameters of research evaluation, REP, output of research, ORP and performance units, PU. Design of the research study is founded on survey of the related literature expressed by an investigation stage realized with curiosity and a critical analysis. The reflections of the approach can provide an innovative education methodology in engineering not only in graduate but also in undergraduate levels.
\end{abstract}

Keywords - Experimental research, Research evaluation parameter; REP, Output of research parameter; ORP, Performance unit; PU.

\section{INTRODUCTION}

Although the methodology utilized- preferred for the research in engineering depends mainly on style of supervision - personality, nature of topic and state of art are the governing items. The survey of the literature which provides the state of art with its restrictions and availabilities leads the researcher to an effective understanding with enough curiosity. The algorithm of the research is based upon a complete analysis on the definition of sub-problems to clear the ambiguous points, lines, even spaces in the topic. The final stage is the design of the research. Therefore conduction of research and the evaluation of the outputs are in fact the realization of the approach. The case studies referred are given in Table 1, listing the experimental research studies conducted on a variety of topics by the author.

\section{PRESENTATION OF THE ALGORITHM}

The experimental research studies are based on the algorithm which had the basic stages of investigation (with curiosity), analysis and design. The state of art on the selected study topic should be well-defined and understood. The "literature survey" is the starting phase which is usually be tried to be passed as rapid as possible by the researchers. However the time paid in the investigation makes the researcher to clearly define the basic points of the investigation offering the research sub- titles even. Furthermore investigation results in the complete understanding to devise an original contribution to the relevant literature. In the discussed case studies, following steps are preferred in the investigation stage:

- Updated literature on the study topic

- Learning about the theoretical basics an $\mathrm{d}$ terminology

- Classification of the literature in terms of a) experimental b) theoretical c) experimental+ theoretical studies

- Presentation of the investigation in terms of tabular manner based upon the common terminology

Investigation with success is through a critical and objective review on the manner with a sound knowledge on the state of art highlighting the unknown points for further research. The curiosity in this stage is very important. Why? what? by who, when and how? are the major questions asked. Investigation on a variety of independent studies conducted by different researchers at different times and with different purposes should be criticized with curiosity. Since even the mixed terminology, different approaches cause introduction of new terms, $\mathrm{p}$ arameters ,specification of the study topics and outline of the state of art which can be regarded as original contributions to the related literature as can be seen from the sample paper[2].

The analysis on the review study is realized through the following steps:

- The basics of the experimental set-up measurement means

- The basic points-study problems 
- The limitations and the ranges of the experimental study

- The methodology used for the analysis of experimental measurements

- The methodology for the presentation of the outputs

- Estimation of the time table of the research

The algorithm is ended with the design stage in which the following steps are existing:

- Specification of the main topic of the research with estimated borders with a well defined aim

- Design of the experimental test system together with measurement and data acquisition system

- Design of the experimental study -sub titles in conformity with the outcome of the analysis of review study.

The followed algorithm makes the researcher ready to start the experimental study which has well defined sub- titles which are called as "test cases".

\section{MEASURES ON THE PERFORMANCE OF THE ALGORITHM}

The performance of the research can be evaluated in terms of sound measures. The estimated time and budget of the research study at the proposal stage and the changes in the realization phase should be compared at the end phase of the study considering the research evaluation parameters ; REP which can be defined in terms of the following items:

$\mathrm{REP}_{\text {budget: }}$ The difference between the amounts of budget at the proposed phase and at the end phase

$\mathrm{REP}_{\text {time }}$ : The suitability with the estimated time -work flow chart during the research

$\mathrm{REP}_{\text {target }}$ : The achievement of targets timely during the research

The parameters expressing the outputs of the research, ORP should be well defined as outputs in terms of incomes of research team, institute/company/organization and national/ international community /universe which can be classified as follows:

$\mathrm{ORP}_{\text {team: }}$ Income of team: Status, knowledge and experience based income of the research team in terms of engineering education at graduate/ undergraduate level, education of academic staff and research staff for industry

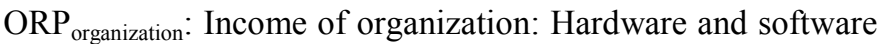
of the constructed test system as a whole which can be utilized during the courses at undergraduate/graduate level

$\mathrm{ORP}_{\text {universe }}$ : Income of national and international community: products / publications/policies of the research as a whole.

As a m easurable quantity ORP universe can be expressed through the performance units PU in terms of 1) number of the academic staff educated, 2) number of the publications in the Journals [5] and 3) the number of citations [5]. Furthermore the yearly averaging of PU can also be regarded as a tool for the determination of success.

\section{CONCLUDING REMARKS}

As can be noticed from Table 1 the referred total time period is 15 years for which $4 \mathrm{PhD}$ and $2 \mathrm{Ms}$ studies were completed. All of the studies are experimental ones supported by either the Research Fund of University of Gaziantep or the Scientific and Technological Research Council of Turkey (TUBITAK) - Engineering Sciences Research Grant Group E.S.R.G.G through the coded research projects. The proposed algorithm was applied in each different study topic with completely different research teams. The design stage of each research was with a complete literature review in terms of a critical analysis with the design of the test system and specification of the sub- titles of the research. The conducted cases are with a total number of 23 research papers published. In the reference list only the sample selected publications are given[1 through 4]. 6 academic staff have completed their academic progress with $4 \mathrm{PhD}$ and $2 \mathrm{MS}$ degrees acquired in mechanical engineering. Since the education of the researcher through a specified topic is the major point of importance; they can be regarded as the verified examples for the success of the approach in engineering education. The discussed cases are having $\mathrm{REP}_{\text {budget, }} \mathrm{REP}_{\text {time }}$ and $\mathrm{REP}_{\text {target }}$ with the average magnitudes of $85 \%, 90 \%$ and $95 \%$ respectively. The resulting $\mathrm{PU}$ are as: $\mathrm{PU}_{1}=0.4$ educated research person/year $\mathrm{PU}_{2}=1.53$ research paper/year and $\mathrm{PU}_{3}=8.67$ citation/year. As a final comment the resulting experience and knowledge in research projects were added to the relevant content of undergraduate courses offered by the author in the mechanical engineering department.

\section{ACKNOWLEDGMENT}

The author would like to express her gratitude for the grant offered by University of Gaziantep.

\section{REFERENCES}

[1] Carpınlıglu M.Ö. and Özahi E.” Laminar Flow Control via Utilization of Pipe Entrance Inserts ( A Comment on Entrance Length Concept) “ Journal of Flow Measurement and Instrumentation ,22 , 165-174 (2011))

[2] Gundogdu M.Y. and Carpinloglu M.Ö. “ Present State of Art on Pulsatile Flow Theory Part I: Laminar and Transitional Flow Regimes", JSME International Journal, 42, 3, 384-397 (1999)

[3] Kanoglu M, Carpınlıglu M.Ö., Yıldırım M.” Energy and Exergy Analyses of an Experimental Open-Cycle Desiccant Cooling System “ Applied Thermal Engineering 24, 919-932 (2004)

[4] Oruc V. and Carpınlıglu M.Ö. “ A Test-rig for the Investigation of Airflow through Collapsible Tubes" Journal of Mechanical Engineering Science Proceedings of Institution of Mechanical Engineers Part C , 221, 275-280 (2007)

[5] Web of Science, Web of Knowledge, Thomson Reuters

Creative Commons Attribution License 4.0 (Attribution 4.0 International, CC BY 4.0)

This article is published under the terms of the Creative Commons Attribution License 4.0

https://creativecommons.org/licenses/by/4.0/deed.en_US 
INTERNATIONAL JOURNAL OF COMPUTERS

TABLE I. COMPLETED RESEARCH STUDIES CONDUCTED IN THE TIME PERIOD 2012-1997

\begin{tabular}{|c|c|c|c|c|c|c|c|}
\hline $\begin{array}{c}\text { Project } \\
\text { Code }\end{array}$ & Research Topic & $\begin{array}{c}\text { Supporting } \\
\text { Organization }\end{array}$ & Duration & Characteristics & $\begin{array}{c}\text { Number SCI } \\
\text { SCI- } \\
\text { Expanded } \\
\text { Papers * }\end{array}$ & $\begin{array}{c}\text { Average } \\
\text { Number of } \\
\text { Papers/Year }\end{array}$ & $\begin{array}{c}\begin{array}{c}\text { Number } \\
\text { of } \\
\text { Citations** }\end{array} \\
\end{array}$ \\
\hline MF 09-09 & $\begin{array}{c}\text { Analysis of } \\
\text { Laminar- } \\
\text { Turbulent } \\
\text { Transition in } \\
\text { Time-Dependent } \\
\text { Pipe Flows }\end{array}$ & $\begin{array}{l}\text { Research Fund of } \\
\text { University }\end{array}$ & $2009-2011$ & Ph. D Thesis & 4 & 2 & 1 \\
\hline $105 \mathrm{M}-301$ & $\begin{array}{c}\text { Collapsible Tube } \\
\text { Flow Dynamics }\end{array}$ & $\begin{array}{l}\text { TUBITAK -MAG } \\
\text { (E.S.R..G.G) }\end{array}$ & $2005-2008$ & Ph. D Thesis & 7 & 2.33 & 4 \\
\hline & $\begin{array}{l}\text { Flow Dynamics } \\
\text { of Packed Beds }\end{array}$ & & $2005-2008$ & MS Thesis & 3 & 1 & 7 \\
\hline MF 99-01 & $\begin{array}{c}\text { Pneumatic } \\
\text { Conveying } \\
\text { System }\end{array}$ & $\begin{array}{l}\text { Research Fund of } \\
\text { University }\end{array}$ & 1999-2001 & MS Thesis & 2 & 1 & 5 \\
\hline MF 97-04 & $\begin{array}{c}\text { Pulsatile Pipe } \\
\text { Flows }\end{array}$ & $\begin{array}{l}\text { Research Fund of } \\
\text { University }\end{array}$ & $1997-2000$ & Ph. D Thesis & 5 & 1.66 & 76 \\
\hline MF 97-05 & $\begin{array}{c}\text { Desiccant } \\
\text { Cooling System }\end{array}$ & $\begin{array}{l}\text { Research Fund of } \\
\text { University }\end{array}$ & $1997-2001$ & Ph. D Thesis & 2 & 1 & 37 \\
\hline $\begin{array}{c}\text { TIME } \\
\text { PERIOD }\end{array}$ & 15 YEAR & $\begin{array}{l}\text { Ph.D /MS } \\
\text { NUMBER }\end{array}$ & $4 / 2$ & $\begin{array}{l}\text { TOTAL PAPER } \\
\text { NUMBER }\end{array}$ & 23 & $\begin{array}{c}\text { TOTAL } \\
\text { CITATION } \\
\text { NUMBER }\end{array}$ & 130 \\
\hline
\end{tabular}

